\title{
To compare the efficacy of ropivacaine with fentanyl v/s levobupivacaine with fentanyl in post-operative epidural analgesia in lower limb and lower abdominal surgeries
}

\author{
Madhuri Sharma $^{1}$, Vaibhav Shahi ${ }^{*}$, Madhu Bhardwaj ${ }^{3}$, Saurabh Varshney $^{4}$, Satyansh Sangal ${ }^{5}$ \\ ${ }^{\mathbf{1}}$ Associate Professor, ${ }^{\mathbf{2}-4}$ Assistant Professor, ${ }^{\mathbf{5}}$ Senior Resident, Shri Guru Ram Rai Institute of Medical \& Health Sciences, Dehradun, \\ Uttarakhand, India
}

*Corresponding Author: Vaibhav Shahi

Email: vaibhavshahi@hotmail.com

Received: $15^{\text {th }}$ February, 2019

Accepted: $27^{\text {th }}$ March, 2019

\begin{abstract}
Aims: To compare the efficacy of ropivacaine V/S levobuivacaine with fenatnyl as adjuvant for post operative analgesia in below umbilicus surgeries under combined spinal and epidural anaesthesia.

Settings and Design: A prospective randomized double blind study was planned on 60 ASA grade I and II patients, admitted for elective surgeries.

Materials and Methods: Patients were randomly divided into two Groups, Group I ( $\mathrm{n}=30)$ received ropivacaine $0.1 \%$ ( $10 \mathrm{ml}$ of $0.2 \%$ ropivacaine) with $2 \mu \mathrm{gm} / \mathrm{ml}$ of fentanyl $(0.8 \mathrm{ml}$ of fentanyl) \& $9.2 \mathrm{ml}$ of normal saline making a total volume of $20 \mathrm{ml}$, Group II (n=30) received $0.1 \%$ levobuivacaine ( $4 \mathrm{ml}$ of $0.5 \%$ levobuivacaine) with $2 \mu \mathrm{gm} / \mathrm{ml}$ of fentanyl ( $0.8 \mathrm{ml}$ of fentanyl) \& $15.2 \mathrm{ml}$ of normal saline making a total volume of $20 \mathrm{ml}$. In both the groups, VAS score at different intervals of time, onset and duration of sensory block, and hemodynamic parameters and complications were assessed.

Statistical Analysis Used: Data was expressed as either mean \pm standard deviation or numbers and percentages and analyses were performed using "Microsoft Excel 2007" for windows. The parameters were analyzed using Student's Paired and Unpaired t-test.

Results: The average duration of sensory block was $276 \pm 30.80$ and $259 \pm 20.95$ min for Group I and Group II respectively which were comparable for both Groups ( $\mathrm{p}>0.05$ ). The hemodynamic changes and complications have no significant differences between two groups, $(\mathrm{p}>0.05)$.

Conclusions: The combination of ropivacaine and levobupivacine with fentanyl as common adjuvant is equipotent for post-operative epidural anesthesia.
\end{abstract}

Keywords: Ropivacaine, Levobupivacaine, Fentanyl, Epidural.

\section{Introduction}

Whether we like it or not, pain is an experience that almost everybody will have to experience at some time. Pain is an unpleasant sensation that accompanies almost all surgical procedures and epidural placement is safe and effective method of providing surgical anesthesia and postoperative analgesia.

Levobupivacaine is an amino-amide local anesthetic drug belonging to the family of n-alkyl substitute pipecoloxylidide.

Levobupivacaine shown to have a safer pharmacological profile ${ }^{1,2}$ with less neurotoxic and cardiotoxic adverse effects. ${ }^{3,4}$ The faster protein binding rate is responsible for decreased toxicity of levobupivacaine. ${ }^{5}$

After buivacaine was noted to be associated with cardiac arrest, Ropivacaine was developed. Ropivacaine was found to have less cardiotoxicity than levobuivacaine in animal models. It is indicated for local anesthesia including central neuraxial blocks and nerve blocks in children and adults.

Fentanyl is synthetic opioid analgesic (a $\mu$ receptor agonist) and a chemical congener of the reversed ester of pethidine. Due to its rapid redistribution and high lipid solubility Fentanyl has short duration of action.

The current study was designed to compare the efficacy of Ropivacaine V/S Levobuivacaine with Fenatnyl as common adjuvant for post operative analgesia in lower limb and lower abdominal surgeries in lumbar epidural.

\section{Materials and Methods}

After approval from the ethical committee of the institute, this prospective randomized double blind study was designed. The study included ASA grade I and II adult patients scheduled for below umblicus surgeries who gave informed consent. Exclusion criteria were patients with communication difficulties, patients for whom central neuraxial block is contraindicated, history of adverse reaction to any study medication, and chronic pain syndrome. Of the 84 subjects, 60 were selected and randomized.

The patients were inserted intravenous cannula into a peripheral vein and preloaded with $15-20 \mathrm{ml} / \mathrm{Kg}$ of Ringer Lactate solution prior to start of combined spinal epidural (CSE) anesthesia. Under all aseptic conditions and after infiltration of the skin with local anesthetic, an 18G Tuohy needle was used to identify the epidural space, by loss of resistance with saline technique, at L3-4 space. An epidural catheter was then advanced in the epidural space upto 5 cms. Test dose of $3 \mathrm{ml}$ Lignocaine with adrenaline $(1: 200,000)$ was injected. The catheter was then anchored in place on the back of patient and then spinal anesthesia was given one space lower than the epidural catheter insertion 
space with $2.5 \mathrm{ml}$ of buivacaine heavy and the case was conducted.

After completion of the case, patient was shifted to post operative ward and when the pain started epidural top up was done with the drugs under study. Patients were randomly divided into two groups Group I and Group II by random number method.

Group I: Patient received $0.1 \%$ ropivacaine $(10 \mathrm{ml}$ of $0.2 \%$ ropivacaine $)$ with $2 \mu \mathrm{gm} / \mathrm{ml}$ of fentanyl $(0.8 \mathrm{ml}$ of fentanyl) \& $9.2 \mathrm{ml}$ of normal saline making a total volume of $20 \mathrm{ml}$.

Group II: Patient received $0.1 \%$ levobuivacaine $(4 \mathrm{ml}$ of $0.5 \%$ levobuivacaine $)$ with $2 \mu \mathrm{gm} / \mathrm{ml}$ of fentanyl $(0.8 \mathrm{ml}$ of fentanyl) \& $15.2 \mathrm{ml}$ of normal saline making a total volume of $20 \mathrm{ml}$.

Patients were assessed for VAS score at different intervals of time, onset and duration of sensory block, and hemodynamic parameters and complications were assessed.

The hemodynamic parameters were monitored continuously for first 60 mins after giving the drug and any changes in hemodynamics greater than $20 \%$ from the baseline value were treated. Bradycardia was defined as heart rate $<60 / \mathrm{min}$. or $>20 \%$ decrease in baseline values; it was treated with inj. atropine i.v. Tachycardia was defined as heart rate $>100 /$ min and Hypotension was defined as mean arterial blood pressure $<60 \mathrm{~mm}$ of $\mathrm{Hg}$ or $>20 \%$ decrease in baseline values, treated with inj. mephentermine $6 \mathrm{mg}$ i.v. in bolus dose.

The visual analogue pain scale (VAS $0=$ no pain, VAS $10=$ worst possible pain) was used to evaluate pain on standard 10 point scale.

(Patient was explained about the scale and post operative analgesia technique during pre-operative period).

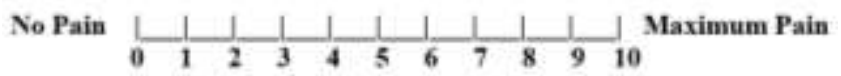

The patient was shown a $10 \mathrm{~cm}$ scale marked as above. They were asked to put a mark across the line that indicates the severity of their pain. Then measure the distance between 'No Pain' to Mark in centimeters.

Pain was further graded as -

0 - (VAS 0) Patient is comfortable.

1 - (VAS 1-3) Mild pain.

2 - (VAS 4-6) Moderate pain

3 - (VAS 7-10) severe pain.

Epidural top up was given to patients having moderate to severe pain. The duration of analgesia was labeled as time interval from this first epidural top up to requirement of first rescue analgesia.

The side effects including hypotension, bradycardia, nausea and vomiting, and shivering were noted and treated.

Data was expressed as either mean $\underline{ \pm \text { standard deviation }}$ or numbers and percentages. All statistical analyses were performed using "Microsoft Excel 2007" for windows. Demographic data were compared using student's unpaired $t$ test. The Student's Unpaired and Paired t-test were used to analyse the monitored and calculated parameters.

\section{Results}

There were no statistical differences in age, body weight, height, and BMI between the groups ( $\mathrm{p}$-value $>0.05$ ).

Table 1: Patient characteristics

\begin{tabular}{|l|c|c|c|}
\hline & Group I $(\mathbf{n = 3 0})$ & $\begin{array}{c}\text { Group II } \\
(\mathbf{n = 3 0})\end{array}$ & $\boldsymbol{p}$-value \\
\hline Age(years) & $27.07 \pm 4.43$ & $27.27 \pm 4.4$ & 0.86 \\
\hline $\begin{array}{l}\text { Bodyweight } \\
(\mathrm{kg})\end{array}$ & $73.93 \pm 7.72$ & $75.9 \pm 8.51$ & 0.35 \\
\hline Height $(\mathrm{cm})$ & $161.53 \pm 4.31$ & $160.33 \pm 4.98$ & 0.32 \\
\hline BMI $\left(\mathrm{kg} / \mathrm{m}^{2}\right)$ & $28.29 \pm 2.04$ & $29.35 \pm 2.08$ & 0.05 \\
\hline
\end{tabular}

$\mathrm{BMI}=$ Body Mass Index

Table 2: Showing different types of surgical operations in different groups

\begin{tabular}{|l|c|c|c|c|}
\hline \multirow{2}{*}{} & \multicolumn{2}{|c|}{ Group I } & \multicolumn{2}{c|}{ Group II } \\
\cline { 2 - 5 } & No. & \% & No. & \% \\
\hline TAH & 9 & 30 & 12 & 40 \\
\hline Appendicectomy & 6 & 20 & 4 & 13.33 \\
\hline Lower Limb Fractures & 10 & 33.33 & 10 & 33.33 \\
\hline Colostomy Closure & 5 & 16.67 & 4 & 13.33 \\
\hline
\end{tabular}

$\mathrm{TAH}=$ Total Abdominal Hystrectomy

Table 3: Onset of analgesia

\begin{tabular}{|l|c|c|c|c|}
\hline Time period (mins) & \multicolumn{2}{|c|}{ Group I } & \multicolumn{2}{c|}{ Group II } \\
\hline & No. & \% & No. & \% \\
\hline $0-5$ & 7 & 23.33 & 15 & 50.00 \\
\hline $5-10$ & 21 & 70.00 & 12 & 40.00 \\
\hline $10-15$ & 02 & 6.66 & 03 & 10.00 \\
\hline $15-20$ & 00 & 00.00 & 00 & 00.00 \\
\hline
\end{tabular}

Table shows that the onset of analgesia was around 510 minutes in most of the subjects in each group.

Onset was slightly delayed in Group I; 70\% patients took 5-10 min

On the other hand in Group II; there was slightly earlier onset $0-5$ mins in $50 \%$ of patients.

Table 4: Duration of analgesia

\begin{tabular}{|l|c|c|c|c|}
\hline \multirow{2}{*}{ Time period (Hrs) } & \multicolumn{2}{|c|}{ Group I } & \multicolumn{2}{c|}{ Group II } \\
\cline { 2 - 5 } & No. & \% & No. & \% \\
\hline $0-2$ & 04 & 13.33 & 03 & 10 \\
\hline $2-4$ & 09 & 30.00 & 10 & 33.33 \\
\hline $4-6$ & 13 & 43.33 & 15 & 50 \\
\hline $6-8$ & 04 & 13.33 & 02 & 6.67 \\
\hline Mean \pm SD (min) & \multicolumn{2}{|c|}{$276 \pm 30.80$} & \multicolumn{2}{|c|}{$259 \pm 20.95$} \\
\hline
\end{tabular}

Table shows that in both the groups the duration of analgesia was around 4-6 hrs. 
Table 5: Showing VAS score \& statistical comparison at different intervals in different groups postoperatively (Mean $\pm \mathrm{SD})$

\begin{tabular}{|c|c|c|c|c|c|c|c|c|}
\hline \multicolumn{2}{|r|}{ Group } & 0 min & $30 \mathrm{~min}$ & $1 \mathrm{hrs}$ & $2 \mathrm{hrs}$ & $3 \mathrm{hrs}$ & $4 \mathrm{hrs}$ & $5 \mathrm{hrs}$ \\
\hline \multirow{3}{*}{ I } & & $4.15 \pm 3.09$ & $0.20 \pm 0.41$ & $0.05 \pm 0.22$ & $0.30 \pm 1.12$ & $2.15 \pm 3.25$ & $3.15 \pm 3.25$ & $4.30 \pm 3.20$ \\
\hline & $\mathrm{t}$ value & & 6.940 & 7.249 & 6.415 & 2.442 & 1.221 & 0.184 \\
\hline & $\mathrm{p}$ value & & $<0.001 \mathrm{HS}$ & $<0.001 \mathrm{HS}$ & $<0.001 \mathrm{HS}$ & $<0.05 \mathrm{MS}$ & $>0.05 \mathrm{NS}$ & $>0.05 \mathrm{NS}$ \\
\hline \multirow{3}{*}{ II } & & $4.30 \pm 3.20$ & $0.20 \pm 0.30$ & $0.10 \pm 0.31$ & $1.05 \pm 2.40$ & $2.85 \pm 3.25$ & $3.35 \pm 1.03$ & $4.60 \pm 3.02$ \\
\hline & $\mathrm{t}$ value & & 6.987 & 7.155 & 4.450 & 1.741 & 1.547 & 0.373 \\
\hline & $\mathrm{p}$ value & & $<0.001 \mathrm{HS}$ & $<0.001 \mathrm{HS}$ & $<0.001 \mathrm{HS}$ & $>0.05 \mathrm{NS}$ & $>0.05 \mathrm{NS}$ & $>0.05 \mathrm{NS}$ \\
\hline
\end{tabular}

Mean VAS increased after 4-5 hours in most of patients receiving epidural Ropivacaine \& Fentanyl and after 3-4 hours in most of patient receiving epidural Levobuivacaine \& Fentanyl.

Table 6: Showing numbers of patients demanding rescue analgesia at different intervals in different groups

\begin{tabular}{|c|c|c|c|c|c|c|c|}
\hline Groups & 0 min & 1 Hr & 2 Hrs & 3 Hrs & 4 Hrs & 5 Hrs & 6 Hrs \\
\hline I & 00 & 01 & 03 & 02 & 07 & 17 & $* *$ \\
\hline II & 00 & 02 & 06 & 08 & 14 & $* *$ & $* *$ \\
\hline
\end{tabular}

** No patient was left in the Group to give rescue analgesia.

1. At 2 hours, $10.00 \%$ of patient in group I and $20.00 \%$ of patient in group II demanded for rescue analgesia.

2. At 3 hours, $6.67 \%$ of patient in group I and $26.67 \%$ of patient in group II demanded for rescue analgesia.

3. At 4 hours, $23.34 \%$ of patient in group I and $46.67 \%$ of patient in group II demanded for rescue analgesia.

Graph 1: Graphical representation of pulse rate per minute (mean \pm sd) at different intervals

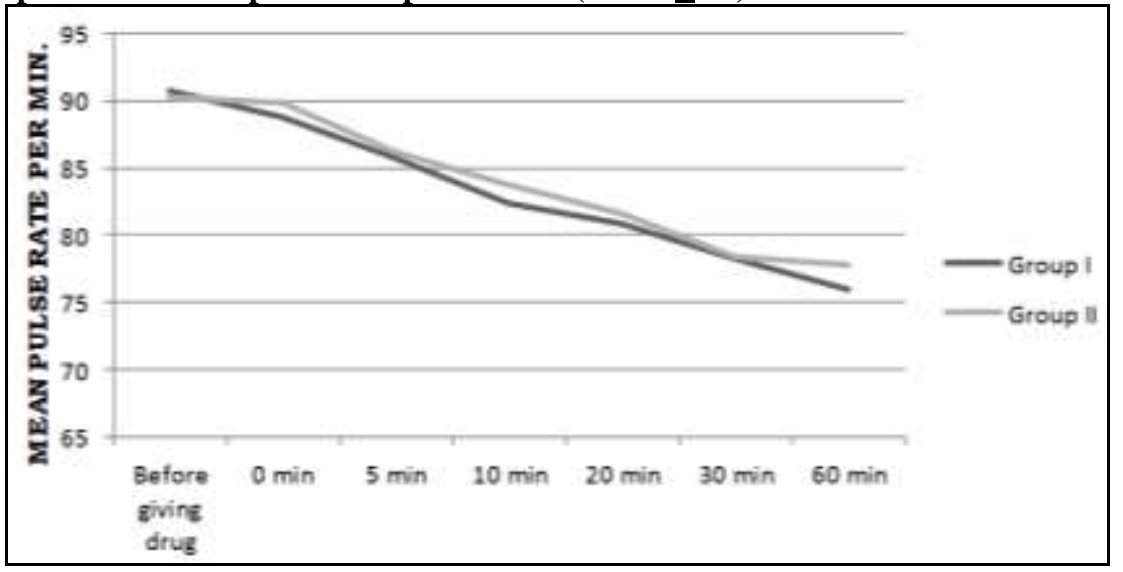

There was decrease in Pulse Rate in both groups after giving the drug but none of patient showed bradycardia at any time.

There was fall in Pulse Rate in both the groups to a statistically significant level after giving the drug ( $\mathrm{p}$ value $<0.05$ ).

Graph 2: Graphical representation of mean arterial pressure $(\mathrm{mm} \mathrm{of} \mathrm{Hg})$ at different intervals

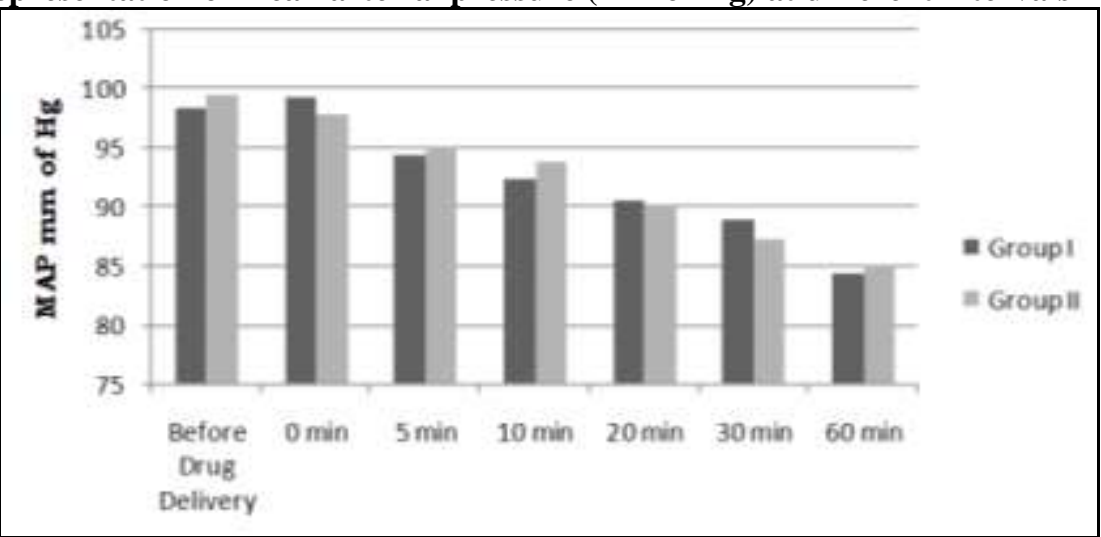

There was significant decrease in Mean Arterial Pressure $(\mathrm{p}<0.05)$ in both groups after giving the drug but none of patient showed hypotension at any time. But the changes in MAP were comparable in both the groups. 


\section{Discussion}

After the evidence of its cardiotoxicity, Levobupivacaine has been developed, as an alternative to bupivacaine, and it seems to have less toxic effects on central nervous and cardiovascular system. ${ }^{6}$

Cox $\mathrm{CR}$ et $\mathrm{al}^{7}$ compared levobupivacaine (two different dosage) with bupivacaine (one dosage) administered epidurally for lower limb surgeries found a significantly longer duration of sensory block with one of dosages of levobupivacaine $0.75 \%$ than bupivacaine $0.5 \%$, this may be due to different dosages used in both studies. The concentration of levobupivacaine used in our study was $0.1 \%$, but in Cox's study the concentration of levobupivacaine used were $0.5 \%$ and $0.75 \%$, i.e. two different doses. The mean duration of sensory blockade in our study was $259 \pm 20.95$ minutes in levobupivacaine with fentanyl group and $276 \pm 30.80$ minutes in ropivacaine with fentanyl group. These results regarding mean duration of sensory blockade depicted the association between the dose and concentration of local anesthetic used. ${ }^{8,9}$ The higher concentration of levobupivacaine used in study by Cox et al. ${ }^{7}$ explains the longer duration of sensory blockade with levobupivacaine $(0.75 \%)$.

The concentration of levobupivacaine solution determines the quality of analgesia, i.e, $0.25 \% 6 \mathrm{~mL} / \mathrm{hour}$, providing better analgesia than same volume more diluted solutions $(0.125 \%$ and $0.0625 \%)$, although some prolongation of the motor blockade may be expected with more concentrated solutions (Murdoch et al 2002). ${ }^{10}$

Previous dose/concentration ranging studies have determined the concentrations of ropivacaine and levobuivacaine for epidural analgesia alone or when combined with adjuvants. The doses used in our study were in accordance to Murdoch et al 2002. ${ }^{10}$

Ropivacaine provides excellent postoperative analgesia by epidural or perineural approach (Agarwal A et al 2010) ${ }^{11}$. Ropivacaine is a relatively new local anesthetic that may have decreased potency for motor block when compared on $\mathrm{mg} / \mathrm{mg}$ basis to buivacaine for epidural use (Zaric D et al 1996). ${ }^{12}$

We have added fentanyl to levobupivacaine as it improves analgesia compared to levobupivacaine or opioid only infusions (Kopacz et al 1999b; Crews et al 1999). ${ }^{13,14}$

Although spinal selectivity of epidural fentanyl is modest compared with morphine, its clinical profile of relatively rapid onset, modest duration, and minimal risk of delayed respiratory depression is better suited to epidural as observed by Liu SS et al 1998. ${ }^{15}$

Casati et al $2003 \mathrm{a}^{16}$ have shown that after equipotent doses of levobupivacaine, bupivacaine and ropivacaine as continuous epidural infusion were associated with excellent postoperative analgesia and similar recovery of motor and sensory functions.

In our study, both epidural solutions produced satisfactory analgesia (Table showing VAS at different intervals) with insignificant decreases in lower-extremity motor function. Our study results were similar to the results of Casati et al 2003a, ${ }^{16}$ showing equipotency of the drugs. In the context of our optimized clinical comparison, $0.1 \%$ ropivacaine appear clinically equipotent to $0.1 \%$ levobuivacaine for analgesia when combined with fentanyl for post operative analgesia via epidural.

There have been several previous studies examining relative potencies of motor and sensory block of epidural levobuivacaine versus ropivacaine. Senard et al $2004{ }^{17}$ have shown that after equal doses of levobupivacaine and ropivacaine the haemodynamic effects and quality of pain relief are similar in patients for post operative pain control via epidural route, but ropivacaine-receiving patients were able to walk around earlier.

There was no bradycardia, or any hypotension in either of the groups. In contrast Kopacz et $\mathrm{al}^{18}$ reported that hypotension as the most common side effect and was experienced by the patients in both treatment groups at the start of surgery (21\% levobupivacaine, $18 \%$ bupivacaine) and during surgery (32\% in both treatment Groups). This may be due to use of higher concentration $(0.75 \%)$ of levobupivacaine and bupivacaine in their study.

\section{Conclusion}

We conclude that $0.1 \%$ levobupivacaine appears to provide equipotent post operative analgesia as compared to $0.1 \%$ ropivacaine with fentanyl as common adjuvant in lumbar epidural in patients for lower limb \& lower abdominal surgeries.

\section{Conflict of Interest: None.}

\section{References}

1. McLeod GA, Burke D. Levobupivacaine. Anaesth 2001;56:331-41.

2. Casati A, Baciarello M. Enantiomeric local anesthetics: Can ropivacaine and levobupivacaine improve our practice? Curr Drug Ther 2006;1:85-9.

3. Huang YF, Pryor ME, Mather LE, Veering BT. Cardiovascular and central nervous system effects of intravenous levobupivacaine and bupivacaine in sheep. Anesth Analg 1998;86:797-804.

4. Morrison SG, Dominguez JJ, Frascarolo P, Reiz S. A comparison of the electrocardiographic cardiotoxic effects of racemic bupivacaine, levobupivacaine, and ropivacaine in anesthetized swine. Anesth Analg 2000;90:1308-14.

5. Burm AG, van der Meer AD, van Kleef JW, Zeijlmans PW, Groen K. Pharmacokinetics of the enantiomers of bupivacaine following intravenous administration of the racemate. $\mathrm{Br} \mathrm{J} \mathrm{Clin}$ Pharmacol 1994;38:125-9.

6. Layek A, Maitra S, Gozi NK. Comparison between intrathecal isobaric ropivacaine-fentanyl and bupivacaine fentanyl in elective infraumbilical orthopaedic surgery; a randomized controlled study. J Anaesth Clin Pharmacol 2015;31(4).

7. Cox CR, Faccenda KA, Gilhooly C. Extradural S (-) bupivacaine: comparison with racemic RS-bupivacaine. $\mathrm{Br} J$ Anaesth 1998;80:289-93.

8. Casimiro C, Rodrigo J, Mendiola MA. Levobupivacaine plus fentanyl versus racemic bupivacaine plus fentanyl in epidural anesthesia for lower limb surgeries. Minerva Anestesiologica 2008;74(78):381-91.

9. Foster RH, Markham A. Levobupivacaine. A review of its pharmacology and use as a local anaesthetic. Drugs 2000;59:551-79. 
10. Murdoch JA, Dickson UK, Wilson PA. 2002. The efficacy and safety of three concentrations of levobupivacaine administered as a continuous epidural infusion in patients undergoing orthopedic surgery. Anesth Analg 94:438-44.

11. Ankit Agarwal, R.K. Verma, Shivika Srivastava: Ropivacaine- The Latest Local Anaesthetic in the Indian Market. J Anaesth Clin Pharmacol 2010;26(2):223-8.

12. Zaric D. The effect of continous epidural infusion of ropivacaine $(0.1 \%, 0.2 \%$ and $0.3 \%)$ on nerve conduction velocity and portural control in volunteers. Acta Anaesthesiol Scand 1996;40(3):342-9.

13. Crews JC, Hord AH, Denson DD. A comparison of the analgesic efficacy of $0.25 \%$ levobupivacaine combined with $0.005 \%$ morphine, $0.25 \%$ levobupivacaine alone, or $0.005 \%$ morphine alone for the management of postoperative pain in patients undergoing major abdominal surgery. Anesth Analg 1999;89:1504-9.

14. Kopacz DJ, Sharrock NE, Allen HW. A comparison of levobupivacaine $0.125 \%$, fentanyl $4 \mathrm{microg} / \mathrm{ml}$ or their combination for patient controlled epidural analgesia after major orthopedic surgery. Anesth Analg 1999;89:1497-503.

15. Liu SS, Allen HW, Oisson GL: Patient-controlled epidural analgesia with bupivacaine and fentanyl on hospital wards. Anesthesiol 1998;88:688-95.
16. Casati A, Santorsola R, Aldegheri G. Intraoperative epidural anesthesia and postoperative analgesia with levobupivacaine for major orthopedic surgery: A double-blind, randomized comparison of racemic bupivacaine and ropivacaine. J Clin Anesth 2003;15:126-31.

17. Senard M, Kaba A, Jacquemin MJ. Epidural levobupivacaine $0.1 \%$ or ropivacaine $0.1 \%$ combined with morphine provides comparable analgesia after abdominal surgery. Anesth Analg 2004;98:389-94.

18. Kopacz DJ, Allen HW, Thompson GE. A comparison of epidural levobupivacaine $0.75 \%$ with racemic bupivacaine for lower abdominal surgery. Anesth Analg 2000;90(3):642-8.

How to cite this article: Sharma M, Shahi V, Bhardwaj M, Varshney S, Sangal S. To compare the efficacy of ropivacaine with fentanyl v/s levobupivacaine with fentanyl in post-operative epidural analgesia in lower limb and lower abdominal surgeries. Indian J Clin Anaesth 2019;6(2):2937. 